\title{
Diagnosis and Endoscopic Treatments of Rectal Varices
}

\author{
Takahiro Sato, Katsu Yamazaki and Jun Akaike \\ Department of Gastroenterology, Sapporo Kosei General Hospital, Sapporo \\ Japan
}

\section{Introduction}

Esophagogastric varices are considered to be the most common complication in patients with portal hypertension, while ectopic varices, that is, those outside of the esophagogastric region, are less common. Rectal varices represent portal systemic collaterals that are manifested as discrete dilated submucosal veins and constitute a pathway for portal venous flow between the superior rectal veins of the inferior mesenteric system and the middle inferior rectal veins of the iliac system. Rectal varices are an infrequent but potentially serious cause of hematochezia. Massive bleeding from rectal varices occurs rarely, with a frequency ranging from $0.5 \%$ to $3.6 \%$ (1-3). In this chapter, we describe the diagnostic modalities and endoscopic treatments for rectal varices in patients with portal hypertension.

\section{Diagnosis of rectal varices}

Endoscopy is the principal method for diagnosis of rectal varices. Endoscopic ultrasonography (EUS) can detect the presence and number of rectal varices better than endoscopy (4). Recently, color Doppler ultrasonography has allowed us to detect fine small blood flow (5). Sato et al. have reported the usefulness of percutaneous color Doppler ultrasonography (CDUS) for the hemodynamic evaluation of rectal varices (6).

Although endoscopic injection sclerotherapy (EIS) (7) and endoscopic band ligation (EBL) (8) for esophageal varices are well-established therapies, there is no standard treatment for rectal varices. In this article, we also review the therapeutic effects and complications of EIS versus EBL on rectal varices in patients with portal hypertension. Several diagnostic procedures have been performed to evaluate rectal varices, including endoscopy, magnetic resonance (MR) angiography, EUS. Endoscopy is the principal method for diagnosis of rectal varices and MR angiography is useful for evaluating the overall portosystemic collateral circulation. On the other hand, conventional EUS $(7.5$ or $12 \mathrm{MHz}$ ) reveals rectal varices as rounded, oval, or longitudinal echo-free structures in the submucosa and also shows perirectal veins outside the rectal wall $(4,9,10)$. With endoscopic color Doppler ultrasonography (ECDUS), color flow images in blood vessels can be obtained, and ECDUS allows for more detailed observation of the hemodynamics of rectal varices than EUS (11). CDUS is a simpler, more non-invasive method than ECDUS and it enables us to detect slight blood flow and to evaluate the portal venous system. Nelson et al. concluded that CDUS was valuable for accurate determination of the direction of portal flow and patency of the vessel (12). Sato et al. have reported the 
usefulness of CDUS for the hemodynamic evaluation of rectal varices and compared velocities of rectal varices with CDUS and colonoscopic findings, and they concluded that CDUS was a useful noninvasive tool in the evaluation of portal hemodynamics, including the observation of blood flow in rectal varices (6).

\subsection{Diagnosis of rectal varices via endoscopy}

Endoscopy is the principal method for the diagnosis of rectal varices; it is a useful modality for diagnosing and observing rectal varices of a certain size and extent, and has a very sensitive predictive value for variceal hemorrhage. The endoscopic findings for rectal varices were evaluated according to the grading system outlined in 'The General Rules for Recording Endoscopic Findings of Esophago-gastric Varices 'prepared by the Japanese Research Committee on Portal Hypertension (13).

The form $(\mathrm{F})$ of the varices was classified as small and straight $\left(\mathrm{F}_{1}\right)$, enlarged and tortuous $\left(\mathrm{F}_{2}\right)$, large and coil-shaped $\left(\mathrm{F}_{3}\right)$, or no varices after treatment $\left(\mathrm{F}_{0}\right)$. The fundamental color of the varices was classified as either white $(\mathrm{Cw})$ or blue $(\mathrm{Cb})$. The red color sign $(\mathrm{RC})$ referred to dilated, small vessels or telangiectasia on the variceal surface. RC shows a high risk of variceal bleeding based on endoscopic findings (Table 1). The following images show: blue color and red color-positive coil-shaped rectal varices (Fig.1-a); blue color and red colorpositive enlarged tortuous rectal varices (Fig.1-b), and a white plug on the rectal variceal surface in a patient with a case of rectal variceal bleeding (Fig.1-c).

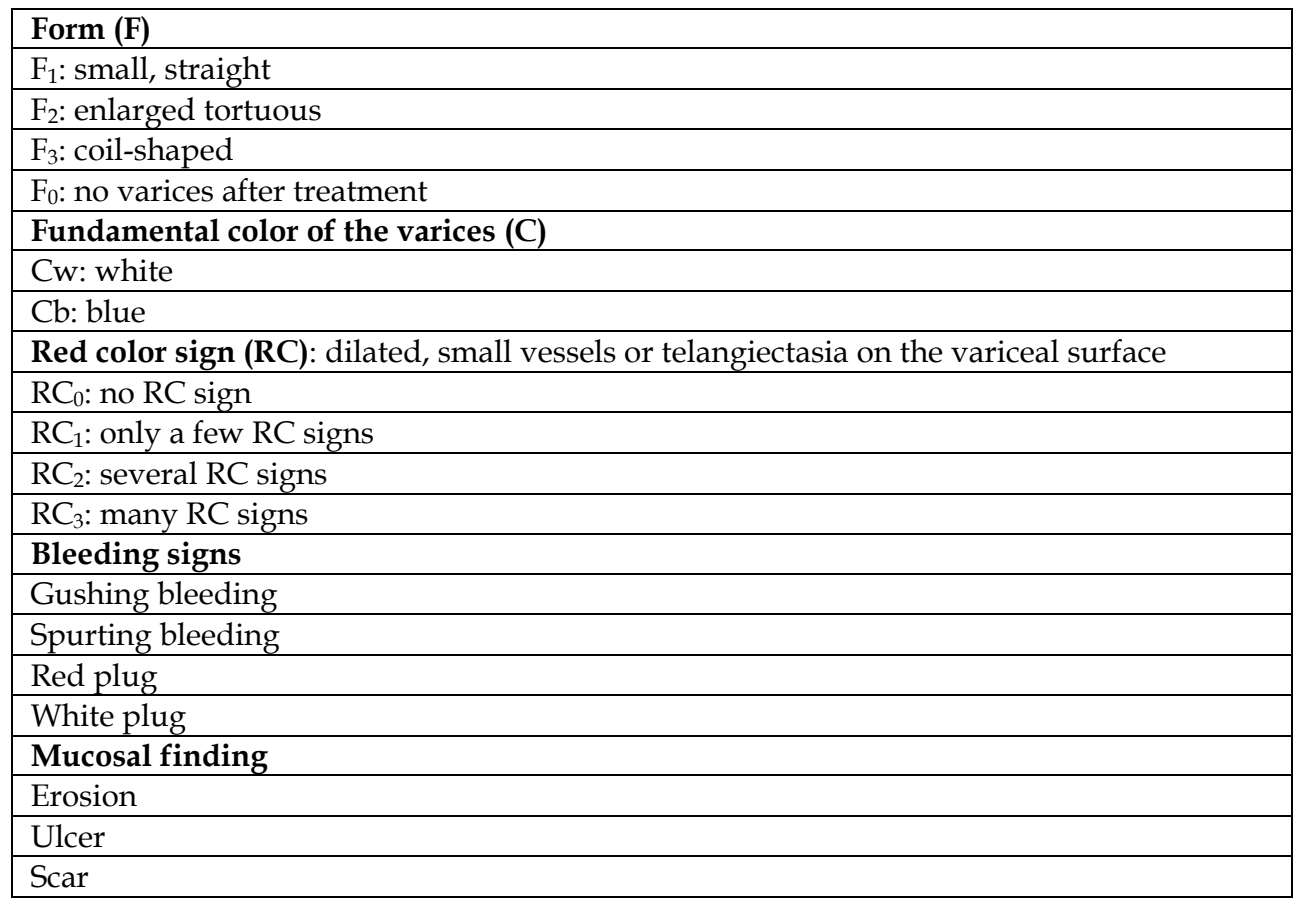

Table 1. The General Rules for Recording Endoscopic Findings of Esophago-gastric Varices prepared by the Japanese Research Committee on Portal Hypertension 


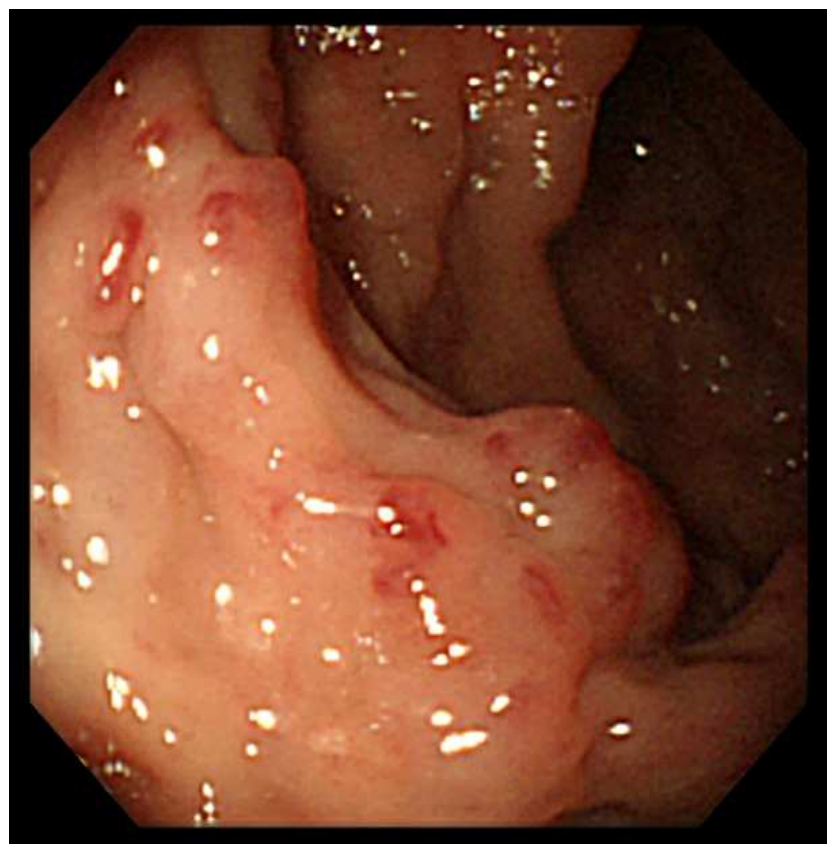

Fig. 1a. Endoscopy showing blue color and red color-positive coil-shaped rectal varices.

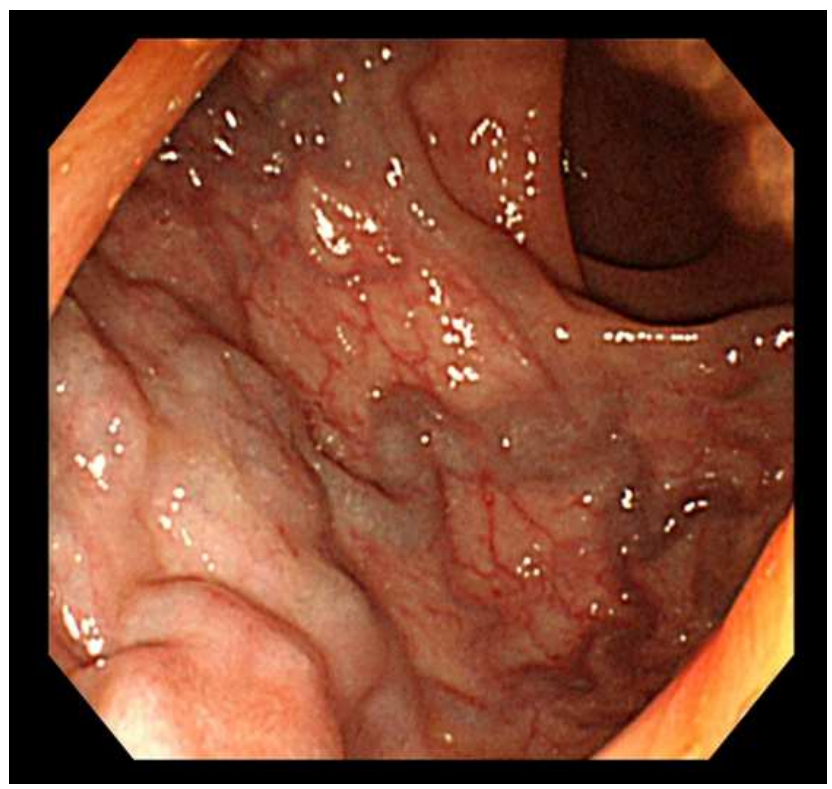

Fig. 1b. Endoscopy showing blue color and red color-positive enlarged tortuous rectal varices. 


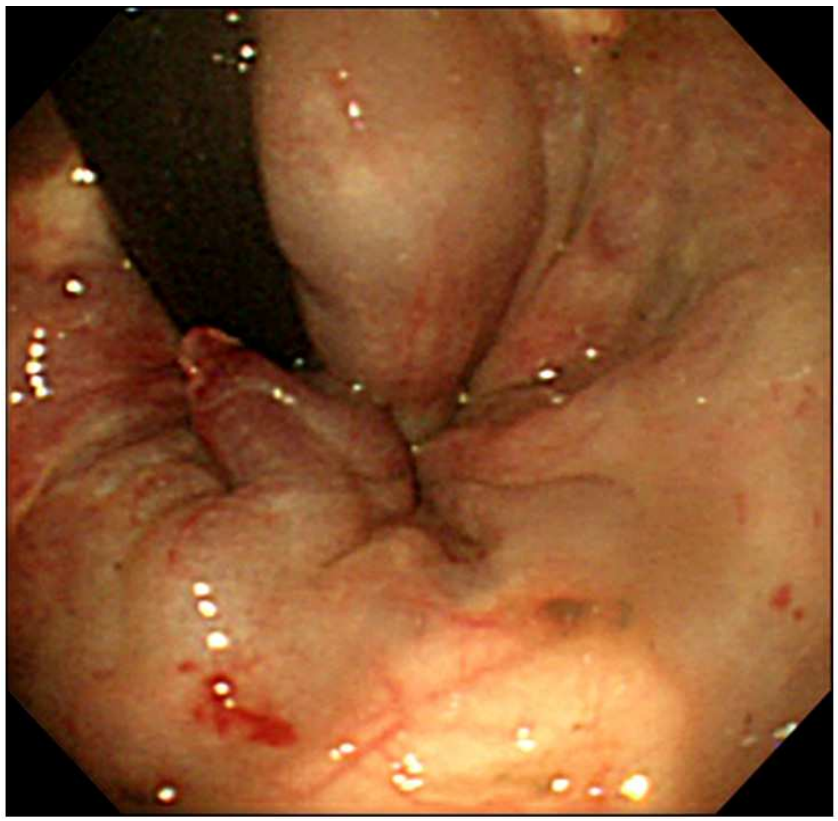

Fig. 1c. Endoscopy show a white plug on the rectal variceal surface in a patient with a case of rectal variceal bleeding.

Hemorrhoids are vascular cushions resulting from arteriolar venous communications in the hemorrhoidal plexus, with no direct communication with any of the major branches of the portal venous system being demonstrated. Fast-Fourier transform analysis of blood flow in the intramural rectal varices showed a continuous wave with a pulsatile wave in some patients. This phenomenon explains the coexistence of rectal varices and hemorrhoids, whereby blood from the hemorrhoids flows into the rectal varices at the anal site, causing a pulsatile blood flow wave from the hemorrhoids (arteriolar venous communication).

\subsection{Diagnosis of rectal varices via endoscopic ultrasonography (EUS) and endoscopic color Doppler ultrasonography (ECDUS)}

EUS has become a useful modality for hemodynamic diagnosis of esophagogastric varices $(14,15)$. The usefulness of EUS $(4,9,10)$ in the hemodynamic diagnosis of rectal varices has been described, and Dhiman et al. found rectal varices via endoscopy in $43 \%$ of patients and via EUS in $75 \%$ of patients with portal hypertension (10). Sato et al. demonstrated that intramural rectal varices, peri-rectal collateral veins, and the communicating veins between intramural rectal varices and peri-rectal collateral veins could be observed clearly via an ultrasonic microprobe (16). ECDUS is better equipped than conventional EUS to visualize in detail the hemodynamics of esophagogastric varices $(17,18)$. With ECDUS, color flow images in blood vessels can be obtained, and ECDUS allows for more detailed observation of the hemodynamics of rectal varices than EUS (11). ECDUS is useful for detecting rectal varices through color flow images, and it is a necessary tool for effective and safe EIS by calculating the velocity of blood flow in rectal varices (Fig.2). 


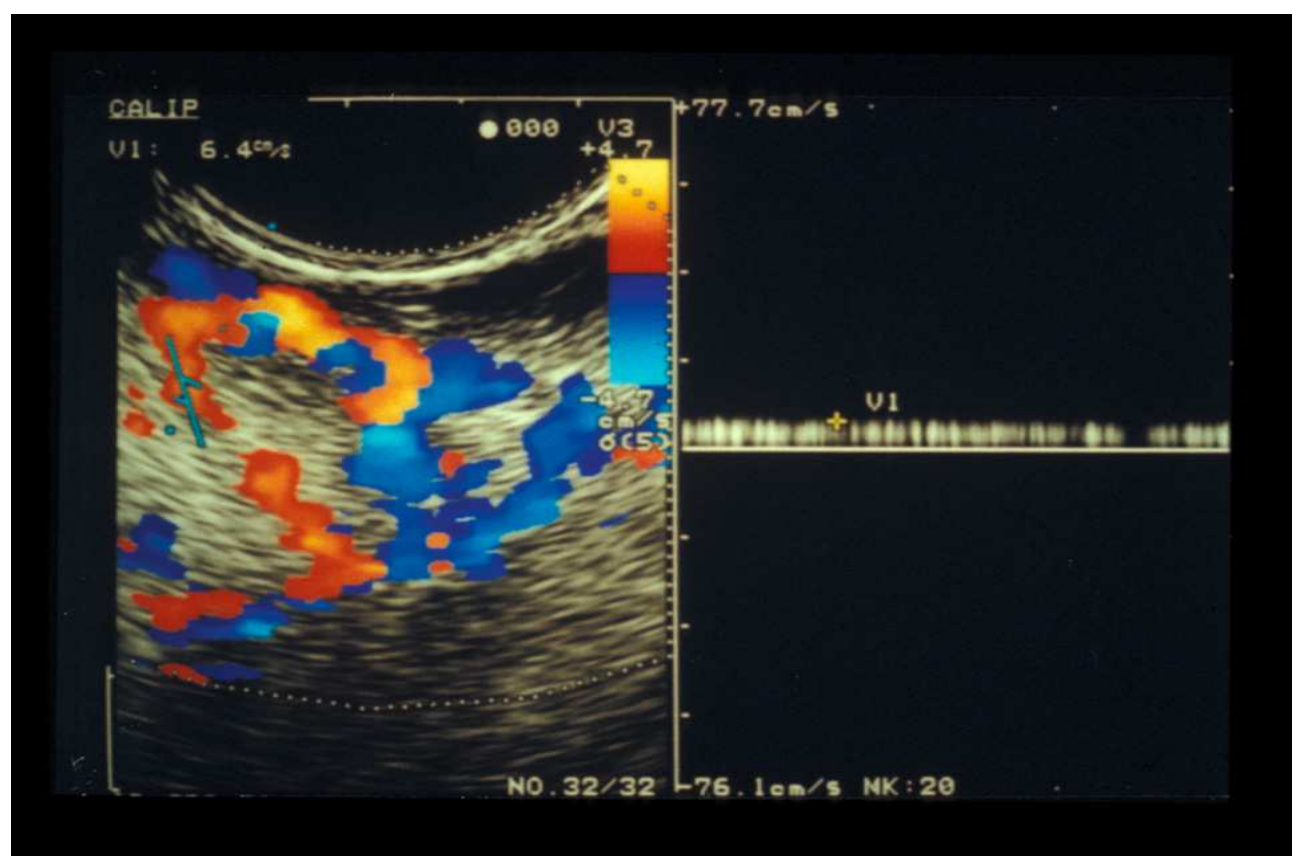

Fig. 2. Color flow images of rectal varices and inflowing vessel with endoscopic color Doppler ultrasonography

\subsection{Diagnosis of rectal varices via percutaneous color Doppler ultrasonography (CDUS)}

Recently, color Doppler ultrasonography has become widely accepted for the assessment of the hemodynamics of abdominal vascular systems, but few color Doppler findings of gastrointestinal varices have been reported. Komatsuda et al. reported the usefulness of CDUS for the diagnosis of gastric and duodenal varices (19), and Sato et al. concluded that CDUS was useful for evaluating the hemodynamics of gastric varices (20). CDUS cannot be performed successfully without a suitable acoustic window. Impediments such as bowel gas, body habitus, and cirrhosis limit the value of sonography for assessing the portal venous system. In addition, with color Doppler sonography, it is difficult to observe the collateral veins situated far from the probe due to the limitations of Doppler sensitivity. The rectal wall was detected at the back area of the vagina in females or prostate in males by sonography and rectal varices could be observed through the bladder filled with urine via color Doppler ultrasonography (Fig.3). 


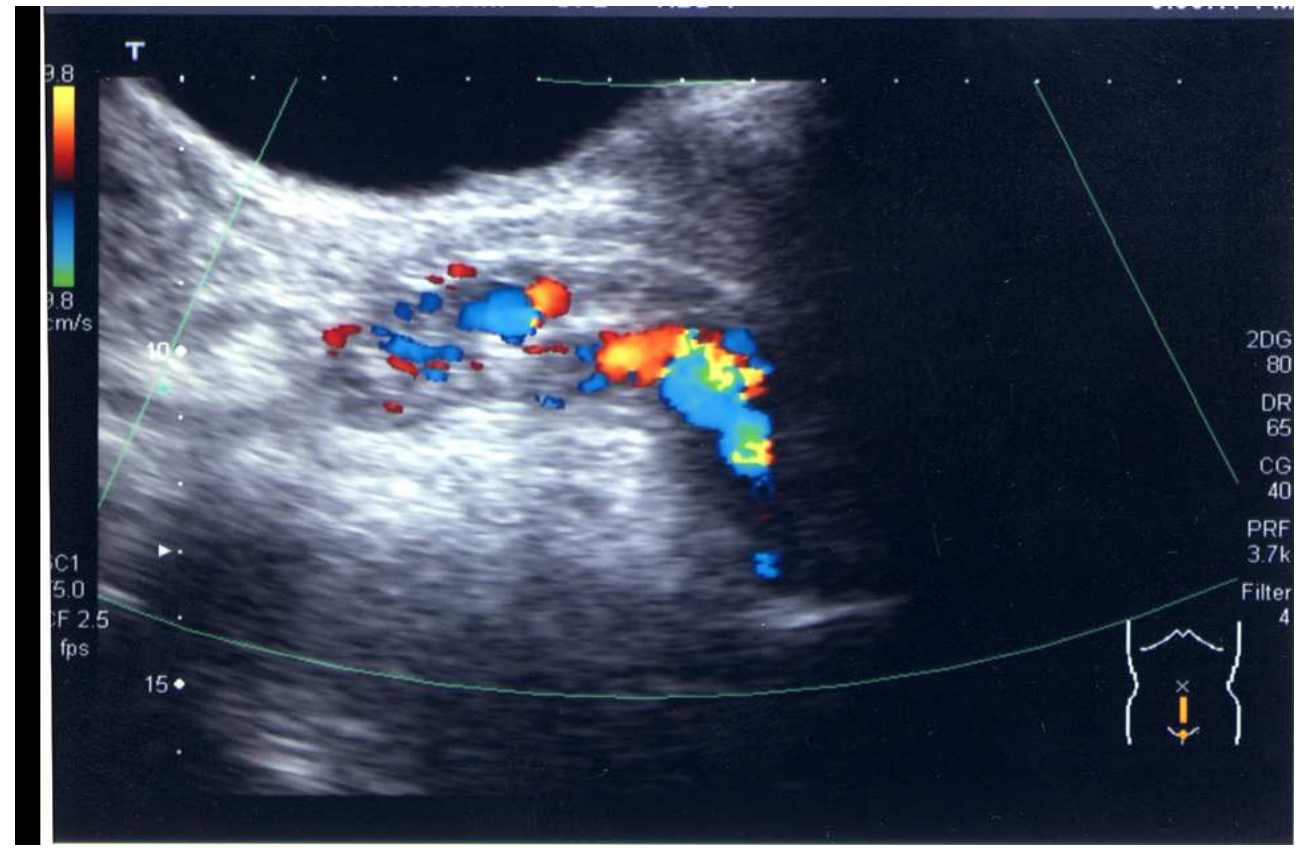

Fig. 3. Color flow images of rectal varices with color Doppler ultrasonography. 
Sato et al. compared the velocities of rectal varices with CDUS and colonoscopic findings (6). The majority of the 44 cases underwent colonoscopy after diagnosis with color Doppler. In this study, the mean velocity of the F2 type rectal varices was significantly higher than that of the F1 type, and the mean velocity of the RC-positive varices was significantly higher than that of RC-negative varices with color Doppler ultrasonography. These results suggest that the measurement of velocity in rectal varices via color Doppler ultrasonography is useful in diagnosing the grade of rectal varices. CDUS is a useful noninvasive tool in the evaluation of portal hemodynamics, including the observation of blood flow in rectal varices.

\section{Endoscopic treatments of rectal varices}

Rectal varices are considered to occur infrequently, however, several articles have reported that they occur with high frequency in patients with hepatic abnormalities (21-23). Hosking et al. reported that $44 \%$ of 100 consecutive cirrhotic patients had anorectal varices (21). Other studies found that the prevalence of anorectal varices was $78 \%$ in 72 portal hypertensive patients (22) and $43 \%$ in 103 cirrhotic patients (23). Although EIS and EBL for esophageal varices are well-established therapies, there is no standard treatment for rectal varices.

Various medical treatments have been used to control bleeding from rectal varices, but none of these is currently considered to be a standard method. Surgical approaches include portosystemic shunting, ligation, and under-running suturing (21). Some investigators have reported that interventional radiologic techniques such as transjugular intrahepatic portosystemic shunts were successfully employed for rectal variceal bleeding (24-26). Several cases of successful treatment of rectal varices with endoscopic treatments have been reported. Wang et al. first reported the usefulness of EIS in treating rectal varices and found it to be effective for controlling bleeding (27). EBL was introduced as a new method for treating esophageal varices, and it is reportedly both easier to perform and safer than EIS. Several cases of successful treatment of rectal varices using EBL have been reported (28-30).

\subsection{EIS for rectal varices}

We performed EIS in 21 of the 30 patients, who were successfully treated without complications. EIS was performed using 5\% ethanolamine oleate with iopamidol (5\%EOI), which was injected intermittently under fluoroscopy. The procedure was performed using a flexible GI endoscope (GIF XQ200; Olympus Optical Co., Ltd., Tokyo, Japan) by a free-hand method, using a 25-gauge injection needle. EIS was repeated every week until the disappearance of all rectal varices and RC signs were confirmed by endoscopy. Fluoroscopic observation with infusion of $5 \%$ EOI was performed to determine the extent of the varices, taking care that $5 \%$ EOI did not flow into the systemic circulation. We decided the amount of $5 \%$ EOI on depiction of passageways (superior rectal vein) of rectal varices. After EIS, colonoscopy revealed shrinkage of the rectal varices in all 21 patients, with no complications reported.

It is necessary to evaluate the hemodynamics of the rectal varices before EIS to avoid severe complications such as pulmonary embolism, and the sclerosant should be injected slowly under fluoroscopy (Fig.4). 


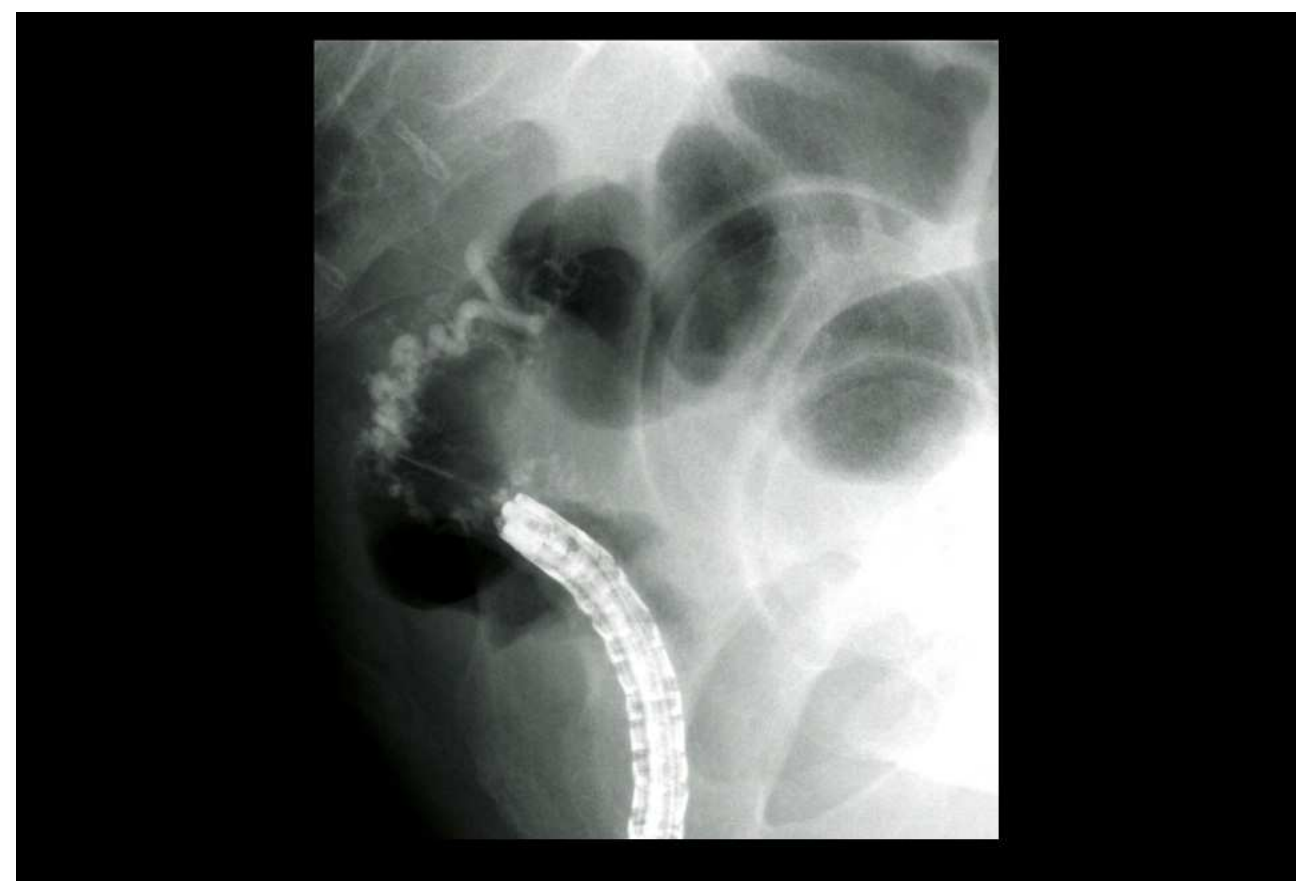

Fig. 4. Fluoroscopic observation with infusion of 5\%EOI was performed.

\subsection{EBL for rectal varices}

EBL was introduced as a new method for treating esophageal varices, and it is reportedly both easier to perform and safer than EIS. Several cases of successful treatment of rectal varices using EBL have been reported. Levine et al. treated rectal varices initially with EIS, and 1 week later, EBL was performed on the remaining rectal varices (28). These investigators described EBL as a safe and effective therapy for rectal varices (30).

EBL was performed in 9 patients on our ward; it was performed weekly using a pneumoactivated EBL device (Sumitomo Bakelite, Tokyo, Japan), and bands were placed on the varices. An overtube was not used during EBL (Fig.5). After EBL, colonoscopy revealed ulcers and improvement of the varices in the rectum of all 9 patients. Eight of the 9 patients experienced no operative complications. However, colonoscopy revealed bleeding from ulcers after EBL in 1 case, in whom endoscopic clipping was performed on the oozing ulcers. 


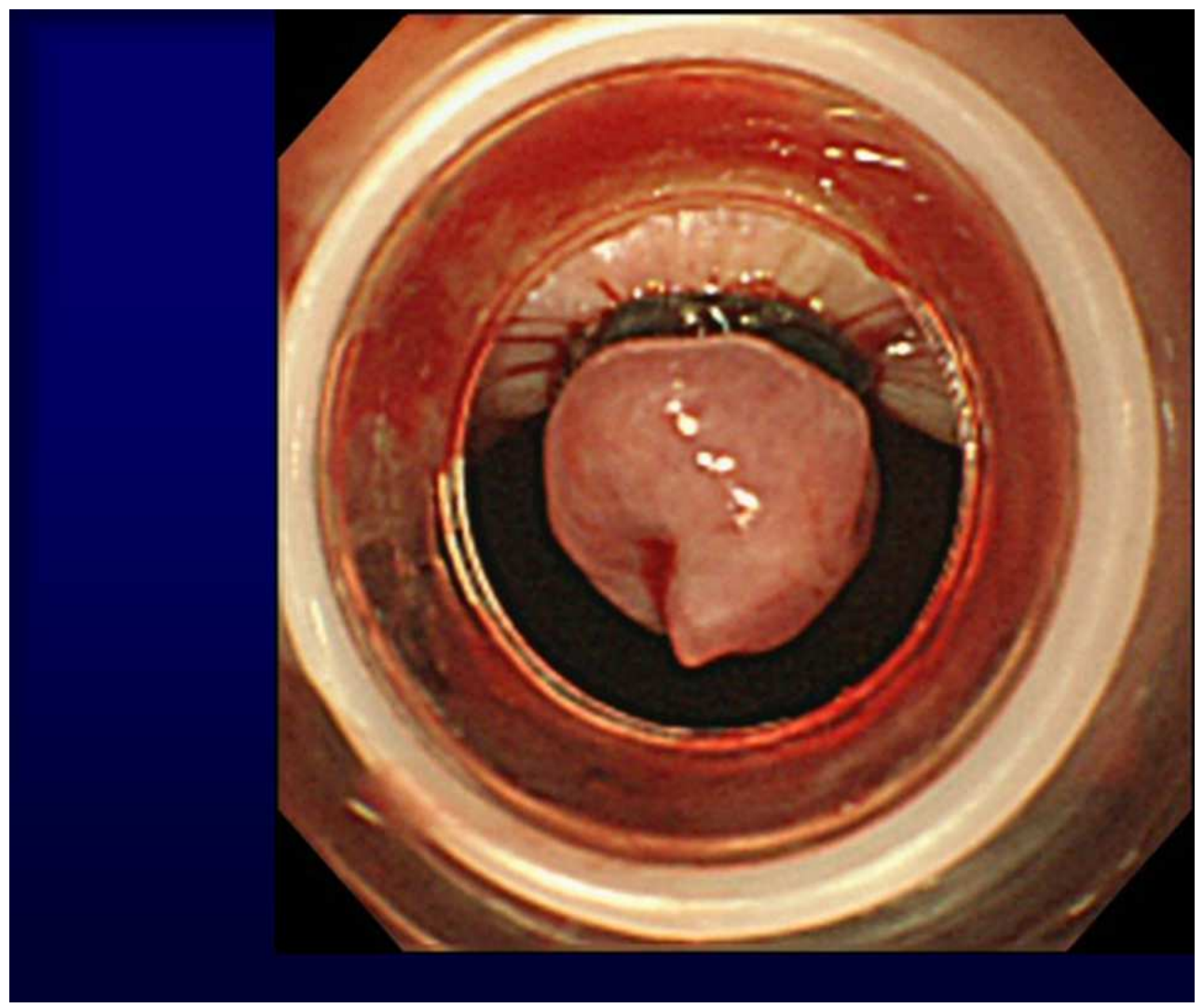

Fig. 5. EBL was performed weekly using a pneumo-activated EBL device.

\subsection{Comparison EIS and EBL for rectal varices}

We have used EIS or EBL to treat rectal varices. In our ward, we retrospectively evaluated the therapeutic effects and rates of recurrence of rectal varices after EIS or EBL. We performed EIS in 21 of the 30 patients, who were successfully treated without complications. The overall recurrence rate for rectal varices over the 1-year follow-up period after treatments was 10 of $24(41.7 \%)$. The patients with recurrence included 5 of the 15 patients $(33.3 \%)$ receiving EIS and 5 of the $9(55.6 \%)$ who received EBL. The recurrence rate was not significantly different between the EIS group and EBL groups, although recurrence tended to be more frequent with EBL.

EBL may be suitable as an initial treatment for rectal varices, but it appears that the varices can easily recur after EBL $(31,32)$. The recurrence rate for bleeding in the EBL group was significantly higher than in the EIS group in our result. All four patients with recurrence of bleeding had been treated using EBL.

EIS appears to be superior to EBL with regard to long-term effectiveness and complications following endoscopic treatment of rectal varices in patients with portal hypertension. More investigations are necessary in larger numbers of patients before evidence-based treatment recommendations can be made. 


\section{Conclusion}

Hemorrhage from rectal varices should be kept in mind in patients with portal hypertension presenting with lower gastrointestinal bleeding. It is difficult to determine the best treatment strategy for rectal varices because of inaccessibility, initial difficulty in diagnosis and subsequent difficulty in treatment.

\section{Acknowledgment}

The authors thank Dr Jouji Toyota, Dr Yoshiyasu Karino, Dr Takumi Ohmura of Sapporo Kosei Hospital, for their help with the manuscript.

\section{References}

[1] McCormack TT, Bailey HR, Simms JM, Johnson AG. (1984). Rectal varices are not piles. Br J Surg 71:163.

[2] Johansen K, Bardin J, Orloff MJ. (1980). Massive bleeding from hemorrhoidal varices in portal hypertension. JAMA 224:2084-5.

[3] Wilson SE, Stone RT, Christie JP, Passaro E. (1979). Massive lower gastrointestinal bleeding from intestinal varices. Arch Surg 114:1158-61.

[4] Dhiman RK, Choudhuri G, Saraswat VA, et al. (1993). Endoscopic ultrasonographic evaluation of the rectum in cirrhotic portal hypertension. Gastrointest Endosc 39:63540.

[5] Ueno N, Sasaki A, Tomiyama T, et al. (1997). Color Doppler ultrasonography in the diagnosis of cavernous transformation of the portal vein. J Clin Ultrasound 25:22733.

[6] Sato T, Yamazaki K, Toyota J, Karino Y, Ohmura T, Akaike J. (2007). Diagnosis of rectal varices via color Doppler ultrasonography. Am J Gastroenterol 102:2253-8.

[7] The Veterans Affairs Cooperative Variceal Sclerotherapy Group. (1991). Prophylactic sclerotherapy for esophageal varices in men with alcoholic liver disease. $N$ Engl J Med 324:1779-84.

[8] Goff GV, Reveille RM, Stiegmann GV. (1988). Endoscopic sclerotherapy versus endoscopic variceal ligation: esophageal symptoms, complications and motility. Am J Gastroenterol 83:1240-4.

[9] Yachha SK, Dhiman RK, Gupta R, et al. (1993). Endosonographic evaluation of the rectum in children with extrahepatic portal venous obstruction. J Pediatr Gastroenterol Nutr 23:438-41.

[10] Dhiman RK, Saraswat VA, Choudhuri G, Sharma BC, Pandey R, Naik SR. (1999). Endosonographic, endoscopic, and histologic evaluation of alterations in the rectal venous system in patients with portal hypertension. Gastrointest Endosc 49:218-27.

[11] Sato T, Yamazaki K, Akaike J. (2006). Evaluation of the hemodynamics of rectal varices by endoscopic ultrasonography. J Gastroenterol 41:588-92.

[12] Nelson RC, Lovett KE, Chezmar JL, et al. (1987). Comparison of pulsed Doppler sonography and angiography in patients with portal hypertension. Am J Roentgenol 149:77-81. 
[13] Idezuki Y. (1995). General rules for recording endoscopic findings of esophagogastric varices. World J Surg 19:420-3.

[14] Caletti GC, Bolondi L, Zani E, Brocchi E, Guizzardi G, Labo G. (1986). Detection of portal hypertension and esophageal varices by means of endoscopic ultrasonography. Scand J Gastroenterol 123:74-7.

[15] Caletti GC, Brocchi E, Ferrari A, Fiorino S, Barbara L. (1992). Value of endoscopic ultrasonography in the management of portal hypertension. Endoscopy 24:342-6.

[16] Sato T, Yamazaki K, Toyota J, et al (2003). The value of the ultrasonic microprobe in the detection and treatment of rectal varices: a case report. Hepatol Res 27:158-62.

[17] Sato T, Higashino K, Toyota J, et al. (1996). The usefulness of endoscopic color Doppler ultrasonography in the detection of perforating veins of esophageal varices. Dig.Endosc 8:180-3.

[18] Sato T, Yamazaki K, Toyota J, Karino Y, Ohmura T, Akaike J. (2008). Observation of gastric variceal flow characteristics by endoscopic ultrasonography using color Doppler. Am J Gastroenterol 103:575-80.

[19] Komatsuda T, Ishida H, Konno K, et al. (1998). Color Doppler findings of gastrointestinal varices. Abdom imaging 23:45-50.

[20] Sato T, Yamazaki K, Toyota J, et al. (2002). Color Doppler findings of gastric varices compared with findings on computed tomography. J Gastroenterol 37:604-10.

[21] Hosking SW, Smart HL, Johnson AG, Triger DR. (1989). Anorectal varices, hemorrhoids, and portal hypertension. Lancet 18:349-52.

[22] Wang TF, Lee FY, Tsai YT, et al. (1992). Relationship of portal pressure, anorectal varices and hemorrhoids in cirrhotic patients. J Hepatol 15:170-73.

[23] Chawla YK, Dilawari JB. (1991). Anorectal varices-their frequency in cirrhotic and noncirrhotic portal hypertension. Gut 32:309-11.

[24] Katz JA, Rubin RA, Cope C, Holland G, Brass CA. (1993). Recurrent bleeding from anorectal varices: successful treatment with a transjugular intrahepatic portosystemic shunt. Am J Gastroenterol 88:1104-7.

[25] Shibata D, Brophy DP, Gordon FD, Anastopoulos HT, Sentovich SM, Bleday R. (1999). Tansjugular intrahepatic portosystemic shunt for treatment of bleeding ectopic varices with portal hypertension. Dis Colon Rectum 42:1581-5.

[26] Fantin AC, Zala G, Risti B, Debatin JF, Schopke W, Meyenberger C. (1996). Bleeding anorectal varices: successful treatment with transjugular intrahepatic portosystemic shunting (TIPS). Gut 38:932-5.

[27] Wang M, Desigan G, Dunn D. (1985). Endoscopic sclerotherapy for bleeding rectal varices: A case report. Am J Gastroenterol 80:779-80.

[28] Levine J, Tahiri A, Banerjee B. (1993). Endoscopic ligation of bleeding rectal varices. Gastrointest Endosc 39:188-90.

[29] Firoozi B, Gamagaris Z, Weinshel EH, Bini EJ. (2002). Endoscopic band ligation of bleeding rectal varices. Dig. Dis. Sci 47:1502-5.

[30] Sato T, Yamazaki K, Toyota J, Karino Y, Ohmura T, Suga T. (1999). Two cases of rectal varices treated by endoscopic variceal ligation. Dig. Endosc 11:66-9.

[31] Shudo R, Yazaki Y, Sakurai S, Uenishi H, Yamada H, Sugawara K. (2000). Endoscopic variceal ligation of bleeding rectal varices: a case report. Dig. Endosc 12:366-8. 
[32] Sato T, Yamazaki K, Toyota J, Karino Y, Ohmura T, Suga T. (2006). The value of the endoscopic therapies in the treatment of rectal varices: a retrospective comparison between injection sclerotherapy and band ligation. Hep Res 34:250-55. 
ENDOSCOPIC PROCEDURES

IN COLON AND RECTUM

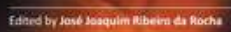

\section{Endoscopic Procedures in Colon and Rectum}

Edited by Prof. Jose Ribeiro Da Rocha
ISBN 978-953-307-677-5

Hard cover, 156 pages

Publisher InTech

Published online 07, November, 2011

Published in print edition November, 2011

Endoscopic procedures in colon and rectum presents nine chapters which start with introductory ones like screening by colonoscopy as the preparation and monitoring for this exam. In addition to these approaches the book aims in the last four chapters to explain endoscopic diagnostic and therapeutic aspects in the colon and rectum. The description of each text is very comprehensive, instructive and easy to understand and presents the most current practices on the topics described. This book is recommended for general and colorectal surgeons as it presents guidelines for diagnosis and treatment which are very well established.

\section{How to reference}

In order to correctly reference this scholarly work, feel free to copy and paste the following:

Takahiro Sato, Katsu Yamazaki and Jun Akaike (2011). Diagnosis and Endoscopic Treatments of Rectal Varices, Endoscopic Procedures in Colon and Rectum, Prof. Jose Ribeiro Da Rocha (Ed.), ISBN: 978-953-307677-5, InTech, Available from: http://www.intechopen.com/books/endoscopic-procedures-in-colon-andrectum/diagnosis-and-endoscopic-treatments-of-rectal-varices

\section{INTECH}

open science | open minds

\section{InTech Europe}

University Campus STeP Ri

Slavka Krautzeka 83/A

51000 Rijeka, Croatia

Phone: +385 (51) 770447

Fax: +385 (51) 686166

www.intechopen.com

\section{InTech China}

Unit 405, Office Block, Hotel Equatorial Shanghai

No.65, Yan An Road (West), Shanghai, 200040, China

中国上海市延安西路65号上海国际贵都大饭店办公楼405单元

Phone: +86-21-62489820

Fax: +86-21-62489821 
(C) 2011 The Author(s). Licensee IntechOpen. This is an open access article distributed under the terms of the Creative Commons Attribution 3.0 License, which permits unrestricted use, distribution, and reproduction in any medium, provided the original work is properly cited. 